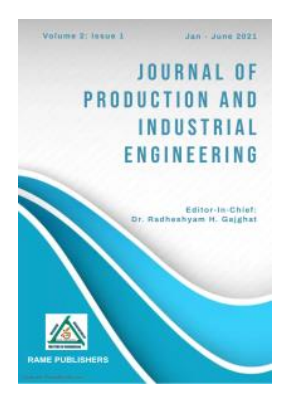

Pavana Kumara ${ }^{1}$ pavan.mech@sode-edu.in

Acharya Shishir ${ }^{2}$ shishir.16me006@ sode-edu.in

Cedric Mathias ${ }^{3}$ cedric.16me024@sode-edu.in

Akash P Patil ${ }^{4}$ akash.16me009@sode-edu.in

Kishora Kumara ${ }^{5}$ kishora.16me040@sode-edu.in

Shri Madhwa Vadiraja Institute of Technology and Management, Dept., of ME, Udupi, India

\title{
Influence of abrasive particles on surface hardness of free cutting brass in ball burnishing process
}

\begin{abstract}
Ball burnishing process is a cold working-based finishing process believed to have more advantages than other conventionally applied finishing techniques. The plastic deformation action during burnishing process increases hardness of burnished surfaces. Turned free cutting brass surfaces were ball burnished in presence of differently sized abrasive particles at various burnishing forces. The effect of abrasive particles size and varying burnishing forces were studied. It was found that the turned surface hardness was improved by 18.67, 17.33, 16\% in dry, fine particle used ball burnishing and medium abrasive particles used ball burnishing process respectively.
\end{abstract}

Keywords - Turning, ball burnishing, abrasive particles, plastic deformation, hardness term

\section{INTRODUCTION}

Conventionally machined surfaces consist of inherently peaks and valleys produced due to various causes such as machining parameters, workpiece and tool settings, machine rigidity, cutting tool conditions etc. Although the necessary precautions are taken while machining, the required or ready to use surface texture cannot be achieved in most of the cases [1]. The surface finish of machined components and method of surface finish achieving also plays a role in deciding surface hardness. Residual stresses[2], corrosion resistance[3], wear resistance[4] are the other surface properties that can be improved by burnishing and are affected by surface finish. Finishing operations like grinding, lapping, honing etc. enhance surface finish but at decreased hardness.

Technical Article - Peer Reviewed

Published online - 26 January 2021

\section{(C) 2021 RAME Publishers}

This is an open access article under the CC BY 4.0 International License https://creativecommons.org/licenses/by/4.0/

Cite this article - Pavana Kumara, Shishir, Cedric, Akash, Kishore, "Influence of using abrasive particles on Surface hardness of free cutting brass in ball burnishing process", Journal of Production and Industrial Engineering, RAME Publishers, vol. 2, issue 1, pp. 8-12, 2021.

https://doi.org/10.26706/jpie.1.2.20200801

In this context, burnishing process becomes interesting by improving many properties in a single step. The surface finish achieved will increase surface hardness due to plastic deformation of surface layers. Compressive residual stresses will be induced and surface will become more wear resistance. Figure 1 shows the schematic representation of ball burnishing process.

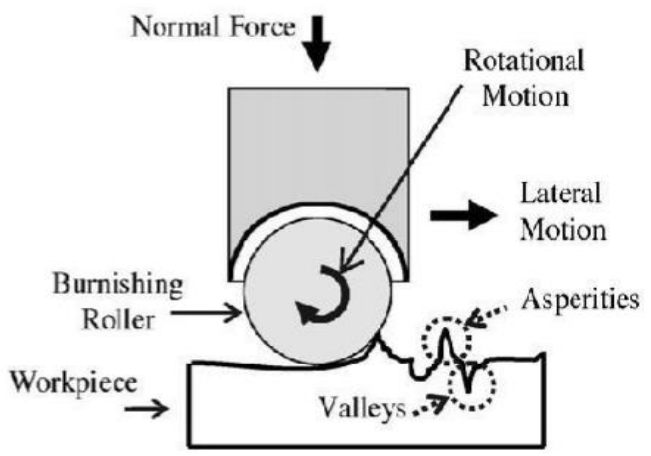

Figure 1. Schematic representation of ball burnishing process [5]

Adel Mahmood Hassan et al. [5] examined the effect of ball burnishing process on aluminum and brass. The results showed that parameters force and number of passes exhibited considerable effect on surface finish and microhardness. N.H.Loh et.al [6] done experimental work based on $3^{4}$ factorial designs on a vertical machining Centre to establish the effects of ball burnishing parameters 
on the surface hardness of flat AISI 1045 specimens. Results shows that ball material, the lubricant, the feed and the depth of penetration parameters have significant effect on the surface hardness and has shown that $33 \%-55 \%$ increase in hardness can be obtained. Dabeer P S et.al [7] carried out ball burnishing on brass and concluded that optimum conditions to obtain higher surface finish were speed of $425 \mathrm{rpm}$, ball diameter of $7 \mathrm{~mm}$, normal force 70 $\mathrm{N}$ and number of tool passes was 2 using surface response methodology. M.Fattouh et.al [8] selected 70/30 Cu-Zn alloy as workpiece material and carried out ball burnishing process. Result presented show that burnishing speed of 20-28 $\mathrm{m} / \mathrm{min}$ and/or burnishing feed less than $0.1 \mathrm{~mm} / \mathrm{rev}$, optimum ball force $15-25 \mathrm{kgf}$ and the optimum number of passes, 3 or 4 produce better surface finish. Tareq A. Abu Shreehah [9] investigated and developed empirical formulas to predict the micro hardness and roughness of leaded brass obtained by burnishing under lubricated conditions of elastic burnishing tool using orthogonal central composite experiment design. High surface micro hardness and good surface finish can be obtained at high spindle speed and No. of passes (namely at $75 \mathrm{~m} / \mathrm{min}$ and 4 passes) and low burnishing force (up to $300 \mathrm{~N}$ ). S. Thamizhmanii et.al[10] demonstrated the research on the multi roller burnishing process on non-ferrous metals namely Aluminum, Brass and Copper to improve surface roughness and surface hardness. C. S.Jawalkar et.al [11] applied Taguchi's design of experiments on the specimens to find optimized values for enhancing the surface quality and hardness economically on EN-8. The standard orthogonal L-9 has been used. The literature study carried out show that the effect of using abrasive particles of various size has not been studied. In current work, effect of using various size abrasive particles at different burnishing force will be studied.

\section{WORKPIECE MATERIALS AND BURNISHING TOOL}

Work piece selected in present study is free cutting brass due to reason that they cannot be easily hardened by the heat treatment. The workpiece is received as cast condition in 22 diameter size from the local market. Table. It gives the chemical composition of free cutting brass.

The ball burnishing tool used in this process as shown in Fig 2 and Fig 3 is self-designed and fabricated. A burnishing tool with interchangeable adopter was designed and fabricated for the experimental tests. This ball burnishing tool can be used in conventional lathe machine tool post without any attachments. Spring used in tool is correlated with deflection and same will be used in measuring burnishing force while carrying out burnishing process. Ball is made from high carbon steel and is hard enough to deform free cutting brass.

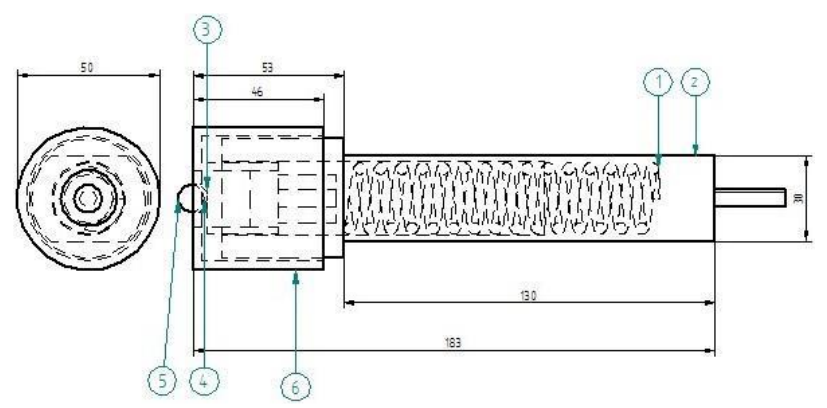

Figure 2. 2D representation of ball burnishing tool

Parts: 1. Spring 2. Lower body 3. Carbide rod holder 4. Ball holder 5. Carbide ball 6. Adopter

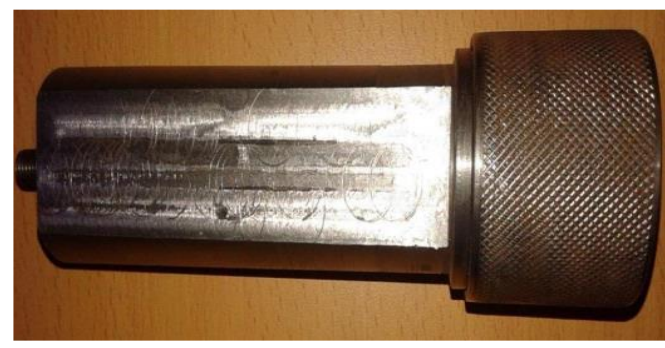

Figure 3. Fabricated ball burnishing tool

TABLE I.

Chemical Composition Of FreE CutTing BRAsS

\begin{tabular}{|c|c|c|c|c|c|c|c|c|}
\hline PB & SN & MN & P & FE & NI & SI & ZN & CU \\
\hline 2.9 & 0.18 & 0.09 & 0.008 & 0.5 & 0.05 & 0.00 & 39. & REM. \\
\hline
\end{tabular}

\section{Methodology}

As mentioned, the burnishing force is the factor which is selected to study its effect on surface hardness during ball burnishing. The other process parameters such as burnishing speed, burnishing feed and number of passes are 
kept constant throughout the experimentation. The experimental plan followed in this study is given in Table III. The following parameters are used at constant levels throughout the study; burnishing feed $=0.1 \mathrm{~mm} / \mathrm{rev}$, burnishing speed=770 rpm, number of passes $=1$. The Brinell hardness value of turned brass was found to be 75 $\mathrm{BHN}$ and burnished samples hardness values are compared with this value.

TABLE II.

EXPERIMENTAL PLAN

\begin{tabular}{|c|c|c|c|}
\hline Sl. No. & Condition & $\begin{array}{l}\text { Abrasive } \\
\text { particle }\end{array}$ & Force levels \\
\hline $1-5$ & $\begin{array}{l}\text { Without } \\
\text { abrasive }\end{array}$ & -- & $\begin{array}{c}\text { Force, } \mathrm{kgf}=5,10,15 \\
20,25\end{array}$ \\
\hline $6-10$ & With abrasive & Fine & $\begin{array}{c}\text { Force, } \mathrm{kgf}=5,10,15, \\
20,25\end{array}$ \\
\hline $11-15$ & With abrasive & Medium & $\begin{array}{c}\text { Force, } \mathrm{kgf}=5,10,15 \\
20,25\end{array}$ \\
\hline
\end{tabular}

The brass rod was first turned to $20 \mathrm{~mm}$ diameter and 16 samples of free cutting brass specimens are prepared with $35 \mathrm{~mm}$ length for burnishing specimen. The hardness values of turned and burnished samples are measured using Brinell hardness equipment. The burnishing experiment were conducted in three stages and are 1. Dry condition i.e. without ball burnishing 2. Ball burnishing using fine abrasive paste 3 . Ball burnishing using medium abrasive paste. The abrasive particles are used in the form of paste and is composed of silicon carbide particles supplied by Carborondum Pvt. Ltd. The fine abrasive particle size is 150 microns and of medium abrasive particle size is 100 microns.

\section{Results AND Discussions}

\section{A. Effect of dry ball burnishing on hardness of brass}

The experiments are carried out without the addition of any lubricants or coolants or abrasive paste in this condition on brass workpiece. The various of level of burnishing force used during the ball burnishing process and hardness values are given in Table II. The parameters burnishing speed, feed and number of passes are kept at constant level. The Brinell hardness testing were carried out at $150 \mathrm{kgf}$ load while measuring hardness of burnished specimens.

As observed from the Fig. 4 and table the hardness value is found to be increasing as burnishing force increases. The higher force values will result in higher hardness values. As force increases the deformation at surface increases to increase hardness. The hardness value of the burnished sample increased up to $89 \mathrm{BHN}$ and this is achieved at 25 $\operatorname{kgf}$ force.

TABLE III.

HARDNESS OF BURNISHED BRASS WORKPIECE

\begin{tabular}{|c|c|c|c|}
\hline Burnishing force, kgf & $1^{\text {st }}$ Trial & $2^{\text {nd }}$ Trial & Average \\
\hline 5 & 82.00 & 84.00 & 83.00 \\
\hline 10 & 89.00 & 83.00 & 86.00 \\
\hline 15 & 80.00 & 82.00 & 81.00 \\
\hline 20 & 88.00 & 86.00 & 87.00 \\
\hline 25 & 90.00 & 88.00 & 89.00 \\
\hline
\end{tabular}

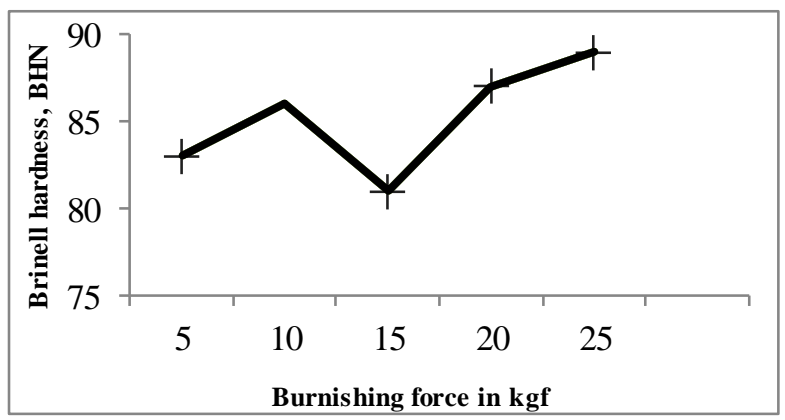

Figure 4. Burnishing force Vs. BHN (Brass)

B. Effect of using fine size abrasive particles on hardness of brass

The experiments are carried out with the addition of fine size abrasive particles in this condition on brass workpiece. The various of level of burnishing force used during the ball burnishing process and hardness values are given in Table IV and other parameters are kept at constant level. The Brinell hardness testing were carried out at $150 \mathrm{kgf}$ load while measuring hardness of burnished specimens.

As observed from the Fig 5 and table the hardness value is found to be increasing as burnishing force increases. The use of abrasive fine particles has not affected much to increase hardness of brass samples. The maximum 
hardness achieved is $88 \mathrm{BHN}$ which is higher than turned sample hardness. Maximum hardness is achieved at $25 \mathrm{kgf}$ force where the deformation of peaks and valleys seams to prominent.

TABLE IV.

HARDNESS OF BRASS BURNISHED USING FINE ABRASIVE PARTICLES

\begin{tabular}{|c|c|c|c|}
\hline $\begin{array}{c}\text { Burnishing } \\
\text { force, kgf }\end{array}$ & $1 \mathrm{st}$ & 2nd & Average \\
\hline 5 & 78.00 & 74.00 & 76.00 \\
\hline 10 & 81.00 & 80.00 & 80.50 \\
\hline 15 & 80.00 & 79.00 & 79.50 \\
\hline 20 & 87.00 & 85.00 & 86.00 \\
\hline 25 & 88.00 & 88.00 & 88.00 \\
\hline
\end{tabular}

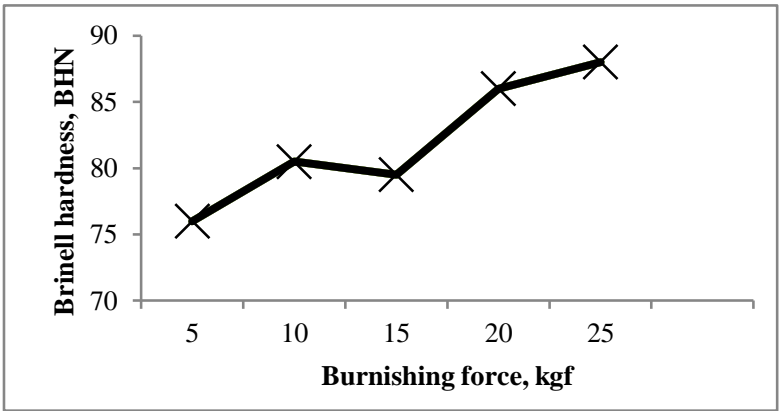

Figure 5. Burnishing force Vs. BHN (Brass)

C. Effect of using medium size abrasive particles on hardness of brass

The experiments are carried out with the addition of medium size abrasive particles in this condition on brass workpiece. The various of level of burnishing force used during the ball burnishing process and hardness values are given in Table 5 and other parameters such as burnishing speed, feed and number of passes are kept at constant level.

As observed from the Fig 6 and table $\mathrm{V}$ the hardness value is found to be fluctuating as burnishing force increases. According to this value for medium abrasive workpiece burnished surface is $7.53 \%$ hardened then the turned surface.
TABLE V.

HARDNESS OF BRASS BURNISHED USING MEDIUM ABRASIVE PARTICLES

\begin{tabular}{|c|c|c|c|}
\hline Burnishing force, $\mathrm{kgf}$ & $1 \mathrm{st}$ & 2nd & Average \\
\hline 5 & 76.00 & 80.00 & 78.00 \\
\hline 10 & 81.00 & 83.00 & 82.00 \\
\hline 15 & 82.00 & 80.00 & 81.00 \\
\hline 20 & 88.00 & 84.00 & 86.00 \\
\hline 25 & 88.00 & 85.00 & 87.00 \\
\hline
\end{tabular}

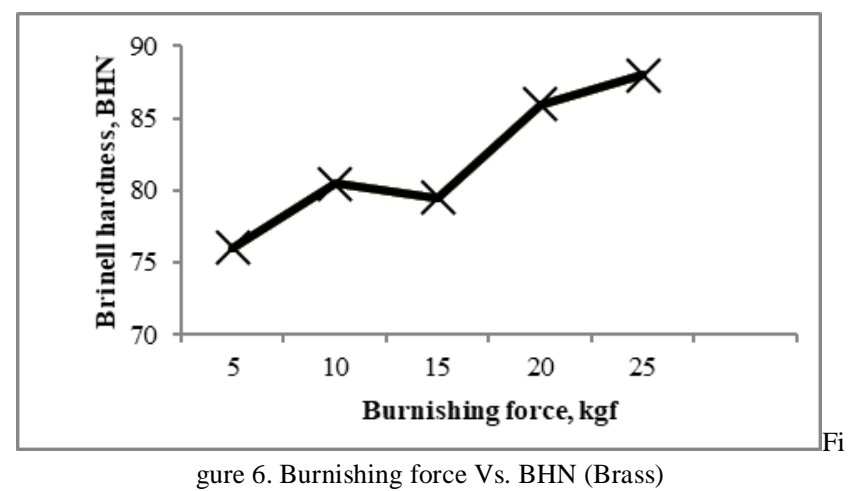

\section{CONCLUSIONS}

The following are the conclusions of this project work;

1. Hardness of a turned brass specimen was $75 \mathrm{BHN}$ and improved to $89 \mathrm{BHN}$ during dry ball improving hardness by $18.67 \%$ with respect to turned sample.

2. In fine abrasive particle used ball burnishing, the hardness improved by $17.33 \%$ with respect to turned sample

3. Using medium abrasive particle the hardness can be improved to $87 \mathrm{BHN}$ which is $16 \%$ greater turned sample.

4. Use of abrasive particles neither improved hardness beyond the level of dry burnishing condition and nor decreased the hardness than turned sample. Hence, more studies are requiring to establish the role of abrasives in burnishing process

5. The higher level of force i.e. $25 \mathrm{kgf}$ have proved to improve the hardness higher than any other level of forces 
in all the cases. Hence, use of higher forces are recommended.

\section{REFERENCES}

[1] S. Ahmad et al., "Optimization of process parameters affecting surface roughness in magnetic abrasive finishing process," Mater. Manuf. Process., vol. 32, no. 15, pp. 1723 1729, 2017.

[2] J. Radziejewska and S. J. Skrzypek, "Microstructure and residual stresses in surface layer of simultaneously laser alloyed and burnished steel," J. Mater. Process. Technol., 2009.

[3] A. Saldaña-Robles, H. Plascencia-Mora, E. Aguilera-Gómez, A. Saldaña-Robles, A. Marquez-Herrera, and J. A. Diosdado-De la Peña, "Influence of ball-burnishing on roughness, hardness and corrosion resistance of AISI 1045 steel," Surf. Coatings Technol., vol. 339, pp. 191-198, Apr. 2018.

[4] G. Devaraya, R. Shetty, S. Srinivas, and V. Neelakanth, "Wear resistance enhancement of titanium alloy $(\mathrm{Ti}-6 \mathrm{Al}-$ $4 \mathrm{~V})$ by ball burnishing process," Integr. Med. Res., vol. 6, no. 1, pp. 13-32, 2016.

[5] A. M. Hassan, H. F. Al-Jalil, and A. A. Ebied, "Burnishing force and number of ball passes for the optimum surface finish of brass components," J. Mater. Process. Technol., vol. 83, pp. 176-179, 1998.

[6] N. H. Loh, S. C. Tam, and S. Miyazawa, "A study of the effects of ball-burnishing parameters on surface roughness using factorial design," J. Mech. Work. Technol., vol. 18, no. 1, pp. 53-61, Jan. 1989.

[7] P. S. Dabeer and G. K. Purohit, "Effect of ball burnishing parameters on surface roughness using surface roughness methodology," Adv. Prod. Eng. Manag., vol. 5, no. 2, pp. 111-116, 2010.

[8] M. Fattouh, M. H. El-Axir, and S. M. Serage, "Investigations into the burnishing of external cylindrical surfaces of 7030 Cu-Zn alloy," Wear, 1988.

[9] T. A. A. Shreehah, "Developing and investigating of elastic ball burnishing tool," pp. 270-279, 2008.

[10] S. Thamizhmanii, B. Saparudin, and S. Hasan, "A study of multi-roller burnishing on non-ferrous metals," vol. 22, no. 2, pp. 95-98, 2007.

[11] C. S. Jawalkar and R. S. Walia, "Study of roller burnishing process on En-8 specimens using design of experiments," vol. 1, no. 1, pp. 38-45, 2009. 